\title{
eCommons@AKU
}

May 2005

\section{Promoting and investigating students' uptake of reflective practice: A Pakistan case}

Jane Rarieya

Aga Khan University, Institute for Educational Development, Karachi

Follow this and additional works at: http://ecommons.aku.edu/pakistan_ied_pdck

\section{Recommended Citation}

Rarieya, J. F. A. (2005). Promoting and investigating students' uptake of reflective practice: A Pakistan case. Reflective Practice, 6(2), 285-294. 
This article was downloaded by: [INASP - Pakistan (PERI)]

On: 11 September 2012, At: 04:09

Publisher: Routledge

Informa Ltd Registered in England and Wales Registered Number: 1072954 Registered

office: Mortimer House, 37-41 Mortimer Street, London W1T 3J H, UK

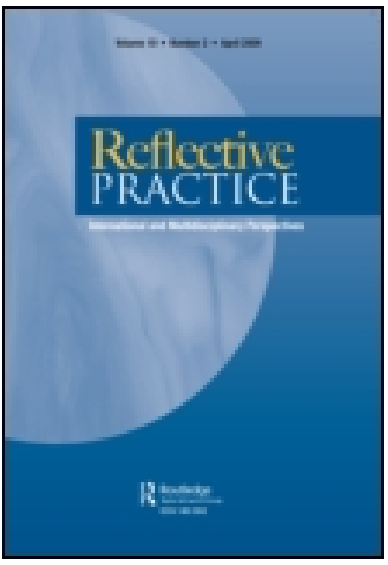

\title{
Reflective Practice: International and Multidisciplinary Perspectives
}

Publication details, including instructions for authors and subscription information:

http:// www.tandfonline.com/loi/ crep20

\section{Promoting and investigating students' uptake of reflective practice: a Pakistan case}

\author{
J ane Rarieya ${ }^{a}$ \\ ${ }^{a}$ Aga Khan University, Pakistan \\ Version of record first published: 20 Aug 2006.
}

To cite this article: J ane Rarieya (2005): Promoting and investigating students' uptake of reflective practice: a Pakistan case, Reflective Practice: International and Multidisciplinary Perspectives, 6:2, 285-294

To link to this article: http:// dx.doi.org/ 10.1080/ 14623940500106518

\section{PLEASE SCROLL DOWN FOR ARTICLE}

Full terms and conditions of use: http://www.tandfonline.com/page/terms-andconditions

This article may be used for research, teaching, and private study purposes. Any substantial or systematic reproduction, redistribution, reselling, loan, sub-licensing, systematic supply, or distribution in any form to anyone is expressly forbidden.

The publisher does not give any warranty express or implied or make any representation that the contents will be complete or accurate or up to date. The accuracy of any instructions, formulae, and drug doses should be independently verified with primary sources. The publisher shall not be liable for any loss, actions, claims, proceedings, demand, or costs or damages whatsoever or howsoever caused arising directly or indirectly in connection with or arising out of the use of this material. 


\title{
Promoting and investigating students' uptake of reflective practice: a Pakistan case
}

\author{
Jane Rarieya* \\ Aga Khan University, Pakistan
}

\begin{abstract}
Today reflection is considered one of the essential principles underlying good teaching practice and teacher education. However, this tacit acknowledgement that teachers need to be reflective practitioners and the development of reflective practice has largely been in the West. Teachers in Pakistan and most of the developing world are generally unaware of what the term 'reflective practice' means. This article presents findings of a study that was undertaken to observe course participants' uptake of an alternate approach to engaging students in reflective practice during a module offered to students in the Masters programme at the Aga Khan University-Institute for Educational Development, Karachi. It describes the practical ways in which students' reflections were generated during the module. It also presents various findings that emerged from these reflective activities, highlighting the successes and challenges of promoting reflection in the said manner. The article further identifies issues that need to be considered if reflective practice is to be nurtured in teacher education institutes in Pakistan and elsewhere in the developing world to ensure the development of reflective teachers.
\end{abstract}

\section{Introduction}

Though reflective practice is now considered a significant component of teacher education, in Pakistan and most of the developing context, the development of reflective practice and the recognition that teachers need to be reflective practitioners is generally nonexistent. Hence, the teachers from South and Central Asia and East Africa, who come to the Aga Khan University-Institute for Educational Development (AKU-IED) for various teacher education programmes encounter the notion of reflective practice for the first time.

The study whose findings are described below was conducted during one of the modules offered to students in the Masters programme at the institute. It was mainly

\footnotetext{
*Corresponding author. IED-PDC, 1-5/B-VII, F. B. Area, Karimabad, PO BOX 13688, Karachi75950, Pakistan. Email: jane.rarieya@aku.edu.
} 
undertaken to observe the course participants' (CPs) uptake of an alternate approach to engaging students in reflective practice. This approach to reflective practice had been developed for two reasons:

1. As tutors of the course, we wanted to ensure that reflection was more than a stated aim of the programme, existing essentially in the 'realm of theory'. Hence, we built in reflective activities into our course so that the CPs' reflections could become more visible for discussion and analysis.

2. The other purpose was to facilitate and develop CPs' reflective skills which were still proving elusive despite having been in the M.Ed. programme for several months, where reflective practice is supposed to be an integral part of the modules taught in the Masters programme.

In this article, I describe the practical ways in which students' reflections were generated during the module. I also present various findings that emerged from these reflective activities and highlight the successes and challenges of implementing reflective practice in these ways. Finally, I identify issues that would need to be considered if reflective practice is to be nurtured in teacher education institutes in Pakistan and elsewhere in the developing world so as to ensure that the development of reflective teachers is a definite outcome of their programmes.

\section{The context}

The Masters in Education programme offered at the AKU-IED is a two-year course in which reflective practice is an integral part and thus various forms of reflective practice are practised in each of the courses offered in the programme. Besides the general acceptance that reflection is closely linked to good practice in teaching and effective teacher education (Zeichner, 1994), AKU-IED has adopted reflective practice for the following reasons:

The Masters programme is offered to practising teachers who are usually considered to be among the best teachers in the institutions from where they come with the purpose of developing them into teacher leaders and change agents in their institutions. The teachers often have years of experience of 'successful' teaching and often believe that their practices are effective. Hence, at the onset of the programme, a number are usually resistant to change in practice and attitude advocated at AKU-IED. Although, the programme aims at enhancing the participants' pedagogy and pedagogical content knowledge, it also aims at creating an attitudinal shift among the CPs in the way they view the entire teaching enterprise. Hence, reflective practice is used as a vehicle to enable the CPs reconceptualize their understanding of the functions, processes and outcomes of teaching.

Reflective practice also provides the students with the opportunity to mull over issues, content and teaching strategies that they encounter daily in classrooms with a view to determine their practicality and application in classrooms. This is because most of the ideas and teaching strategies used at AKU-IED, though typical of current trends in education, are novel to the students, and quite often for these teachers who 
have been teaching 'successfully', the 'do-ability' of some of the ideas presented is questionable. Hence, stepping back and thinking of how this can be done is quite an important step in their adoption of the propagated practice.

Last but not least, continually engaging students in reflection is intended to get them into the habit of reflecting, making it a part of their practice and thereby, reflective teachers for life. The underlying principle at AKU-IED for developing teachers into reflective practitioners is to enable teachers to re-enter the profession 'with dispositions and skills that will enable them to continue to learn from experience' and to 'become better at teaching throughout their careers' (Gore \& Zeichner, 1991, p. 119).

At AKU-IED, CPs enact reflective practice through maintaining reflective journals, participating in reflective discussions, engaging in action research and doing assignments which are usually reflective in nature.

All the above forms of reflection do not necessarily take place concurrently in any one given course.

\section{Generating an alternate approach to reflection}

Despite the aforementioned opportunities for reflection, we had noticed that not all students take to reflective practice with ease and that quite often the levels of reflection remained at the technical level-mere descriptions of events. We, therefore, wanted to go beyond merely encouraging the CPs to reflect. Hence, in designing our course, we deliberately developed a strand of reflective practice whose aim was to enable the CPs appreciate the value of reflection as a meaningful way of approaching learning about teaching so that a better understanding of teaching English and teaching in general, might develop.

As a result, CPs engaged in reflection at three levels:

- Writing reflections on a regular basis in their reflective journal and sharing the entries with the tutors.

- Creating time either at the start of the day or end of day for CPs to quietly reflect on sessions.

- Sharing the written reflections with the whole class.

With the help of my colleagues, I closely monitored these processes of reflection. The teaching team also took part in these processes in varying degrees. I analysed journal entries for depth and range of reflections, noted observations during the sharing sessions and at the end of the course, I asked the CPs to respond to a questionnaire on their experiences of reflective practice during the course.

The aim of conducting reflective practice in this manner was three-pronged:

- To facilitate students' uptake of reflective practice.

- To enable the course participants think deeply of issues raised/course content/ teaching strategies/activities advocated or used and thereby develop a deeper understanding and appreciation of them.

- To inform the tutors about their pedagogy of practice. 


\title{
CPs' response to the reflective process
}

At the start, the initiative of what and how to write was initially left to the CPs because we assumed that since they had been engaged in reflective practice in previous modules, the process of reflection would not be a challenging one. Contrary to this assumption, tuning into writing at the initial stage seemed difficult for the CPs. They appeared to have problems gathering their thoughts together and asked for guidelines on what to write about and how. They also did not share their reflective journals unless the tutors asked for them and found it difficult to respond to reflections without prompting from the tutors. Even sharing their reflections verbally with peers during the provided time had to be initiated by the tutors. Perhaps, the reasons for this response, lie in the following statements made by the CPs about the process of reflection:

First of all, CPs should be given opportunities on how reflections will be written. It is because I was not clear about how to write reflections in appropriate manner. I was just writing the learning points and challenges but was not mentioning how I learnt and why I learnt effectively.

It [sharing reflections with the class] allows for fewer participants to voice their critiques due to the complexity of having to listen and then raise questions. Another reason is that a topic which is valuable to one may not be to another and less attention may be paid.

However, as the course unfolded and reflecting became routine, CPs reflected without much push from us, as evidenced in the following excerpt:

\begin{abstract}
In the beginning, I was writing my reflection generally on every event that happened in the classroom. Writing daily reflections and sharing with [tutors] enabled me to write reflections that were specific and discuss an aspect in detail. So I was able to analyse the positive aspects, implications and challenges of the success of any session and any interesting event within the session's discussion.
\end{abstract}

\section{Levels of reflection}

Reflection means so many things to so many people. However, Zeichner and Liston's description of a reflective teacher best captures what we had hoped to see in the CPs' reflections. They describe a reflective teacher as one who:

... examines, frames and attempts to solve the dilemmas of classroom practice; is aware of and questions the assumptions and values he or she brings to teaching; is attentive to the institutional and cultural contexts in which he or she teaches ... (1996, p. 6)

They also believe that reflective teachers evaluate their teaching by asking the broader questions, such as 'are the results good, for whom and in what ways?' (ibid, p.11).

As a result, the analysis of the CPs' uptake of reflection was based on two things.

- Depth: is there evidence of reflection on areas taught or discussed in class? Is there evidence of reflection on underlying causes, principles or philosophies? Is there evidence of relating intended practice to principles identified in the literature or taught in class?

- Nature: does the reflection cover several areas of the taught course? 
Table 1 illustrates the CPs' level of reflections during the module.

Table 2 shows how CPs' reflections were distributed at the beginning of the module. I observed that those who started off at Level 2 at the start of the module comprised students who are fluent in English and whose writing skills are quite advanced. It seemed that those who were least practiced in using English found it more difficult to speak reflectively in English than the teachers who had a wider range of vocabulary, registers and so forth. However, this is not to suggest that being allowed to switch to a language that the CPs are familiar with would result in a more reflective discourse.

Nonetheless, with continuous dialogue between the tutors and CPs, a shift became evident in their levels of reflection. This is reiterated by the following journal entry:

Your [faculty] feedback helped me to improve my reflections. Because before your comments, I used to write the learning outcomes, challenges and issues but after your feedback, I tried to give the reason for learning and challenges and I also thought deeply how to implement what I have learnt in my context. It also helped me to include new things on the basis of facilitator's feedback.

Table 2 also shows the distribution of CPs' reflections by the time the module came to an end. Those who ended up at the transformative level were those who continually engaged in a dialogue with the tutors and in the process became quite immersed in the entire process of reflection. They were also the ones who were able to communicate in English with ease. The ones who were at the 'Noticing' and 'Sense' levels by the end of the module were the ones who reflected infrequently.

From the start of the module, there were some CPs who were more receptive to the idea of engaging in reflection than others. However, they were not necessarily the ones who ended up at the highest level of reflection. They appeared to be the most enthusiastic about engaging in reflective practice as is evidenced by the frequency of their reflections and the questions they asked regarding their reflections.

Table 1 CPs' Levels of Reflections

Level of reflection

4. Transformative

3. Making meaning

2. Making sense

1. Noticing
Representation of reflection

Restructured learning and able to see its applicability. Issues looked at both the micro and macro levels and from various dimensions, e.g., ethical, moral, political, social etc.

Meaningful reflections, able to identify purpose. Explanations with principle or theory given as the rationale. Occasionally looks at issues outside the class but linked to classroom activities.

Highly descriptive of ideas that struck him or her. Critical incidents are described but not analysed. Events are labelled with the appropriate terms.

Factual description. No details given. Simply outlines what happened. Skeletal wording.

Source: an adaptation of Bax and Cullen's (2003) table on stages of learning during a teacher's adoption of reflective practice. 
Table 2 Distribution of CPs' Reflections

\begin{tabular}{lcc}
\hline Level of reflection & Start of module Number of CPs (\%) & End of module Number of CPs (\%) \\
\hline Noticing & 74 & 9 \\
Making sense & 26 & 4 \\
Making meaning & - & 78 \\
Transformative & - & 9 \\
\hline
\end{tabular}

Another possible reason for the above patterns in reflection lay in the purpose for which the CPs wrote their reflections. Most of the CPs' reflections were mainly on what they had been taught and hence they always sought further clarification on how these ideas could be implemented in the classroom. What seemed important to them was the practicality of the ideas. Deeper issues like the purpose of the strategies and philosophy underlying certain approaches to teaching English, among others was only considered after questioning from the tutors.

A further factor that may need to be considered is that the participants were asked to dialogue with the tutors and sharing with peers was done in the presence of their tutors. It is possible that the tutors' participation in this process may have inhibited their ability to reflect critically. Though the tutors did try their best to minimize this threat by, for example, sharing their reflections openly and putting them up for critiquing, thereby passing on the message that critiquing is actually allowed in the classroom.

\section{Preferred forms of reflection}

At the end of the course, CPs were asked to list their order of preference of reflection using the likert scale, with ' 1 ' for most preferred and ' 3 ' for least preferred. Table 3 shows the CPs' order of preference of form of reflection.

Table 3 shows that the popular form of reflection was the journal dialogue between $\mathrm{CPs}$ and tutors. Perhaps, the reason for this preference can be explained by the following responses which they shared:

It [reflective journal] gives me the liberty to write reflections when there is a genuine need to do so and there is ample time for one to write their reflections in a more relaxed atmosphere.

It [reflective journal] proved to be a source to share my learning with my facilitator and get timely feedback for improvement.

Table 3 CPs' Preferred Form of Reflections

\begin{tabular}{lccr}
\hline & \multicolumn{3}{c}{ Order of preference } \\
\cline { 2 - 4 } Form of reflection & 1 & 2 & 3 \\
\hline Journal dialogue & $82 \%$ & $14 \%$ & $4 \%$ \\
Responding to each other's reflections & $10 \%$ & $81 \%$ & $9 \%$ \\
Reflecting at the end or start of sessions & $10 \%$ & $4 \%$ & $86 \%$ \\
\hline
\end{tabular}


It [reflecting at the start or end of day] seemed forced and artificial. It was like a 'timed test' and I, personally was obliged to do it as a requirement of the course work. Otherwise, I did not enjoy doing my reflections that way at all.

However, one CP found all the three modes of reflection important, because:

For me all the three aspects are important because while the reflective journal improved my thinking, writing and organizational skills, reflective discussions and responses developed my confidence.'

\section{Successes}

CPs' journal entries, discussions and teaching portfolios suggest that the CPs had developed a visible reflective stance. This was very evident during the teaching practicum period. They saw reflective practice as a tool of re-looking at their practice. As one of them stated, 'reflective practice enables me to travel into myself and find out the worth of my actions'. They also thought it was an important way 'of maintaining mutual communication with learners'.

The nature of classroom discussions changed in the course of the module. There was more talk of possibilities and adaptations instead of the 'cannot work in my context' thinking. There were multiple views of issues, instead of the one and only 'correct' view as illustrated by the following excerpt:

I learnt that there is more than one reality of an occurrence of any incident and by knowing these realities and thinking about how to deal with the same incident in future, and by thinking about how I will implement things in my classroom, I was engaged in metacognition that helped me to see things from a wider perspective.

The classroom atmosphere and relationships among the CPs and between the CPs and the tutors seemed to have been affected too. Because of engaging in reflective practice in the way that we did, an atmosphere of trust and openness developed in the classroom.

Some of the CPs found engaging in reflective practice cathartic. For example, one of them said:

I felt relieved whenever I communicated certain aspects that negatively and directly related to my learning here at IED. When the faculty looked into these issues (some of them), I felt a burden lifted off my shoulders. There was no better way to show these aspects for fear of being misconstrued.

One of the effects of engaging in reflective practice in the manner we provided was that the CPs' writing skills improved. At the start of the course, the majority of the CPs' writing was rather stilted and reflections were quite brief. However, as the process continued their writing became more relaxed and lengthier.

\section{Challenges}

The demanding nature of the programme discouraged a number of CPs from effectively engaging in reflective practice. For some of them, this was further compounded by their inadequate skills in English. 
For the tutors, the challenge came from an aspect of reflection that is so subtle that it is hardly grasped by many like us in teacher education. During the module, we tended to 'extract' the learning from the CPs' experiences so that it could be presented to them in ways that might be helpful and offer insights that they had not previously recognized. This is a common approach to enable students to be reflective. However, we identified a controversy in this approach. If the focus was genuinely on the CP as learner, then it was their ability to analyse and make meaning from experience that mattered most - as opposed to when we filtered, developed and shared the knowledge with the CP. Who was generating the knowledge? Who was doing the learning? How then could we help our students forge ahead? These were questions that plagued us and yet it was not easy to find answers to them. They were questions that really mattered and we felt are directly related to where effective reflective practice usually occurs.

\section{Implications for teacher education}

Promoting and investigating CPs' uptake of reflective practice brought to my attention issues that I feel that those of us who work with teachers need to consider if teachers in Pakistan and similar contexts are to become reflective.

From the CPs' ability to take up reflective practice and its impact on them, it would be safe to presume that it does have a part to play in teacher education in Pakistan and elsewhere for the basic reason that it enables teachers to see possibilities in improving their practice. This is an important phenomena in a context where teachers' teaching repertoire is quite limited. Scrivener (1994) has suggested a toolkit as a metaphor for good courses which provide participants with the tools whereby they can access the information they need when the need arises because quite often pre-service or in-service courses cannot hope to teach 'trainees' everything there is to know about good teaching. Indeed, reflective practice is one such tool that can help teachers access information both from within themselves and without when they need it.

Since dialogue is central to the process of reflection, teachers need opportunities to be inducted into this kind of professional discourse. Tutors need to demonstrate to students how they can think about what they read, hear or view. Opportunities for acquiring this discourse may be particularly important in courses here in Pakistan or similar regions in which teachers are expected to speak or write reflectively in English which is not their main language. This can further be supported by the fact that though literature abounds on the goals and intentions of reflective practice, it is rather thin on providing guidance for teaching students how to reflect. As Serafini (2002, p. 4) points out:

... teaching from a reflective stance is not something teachers are 'taught to do', rather it is seen as something they are 'helped to become'.

If reflective practice is not something we can be taught to do, then the onus is on us (tutors) to explore how students in our institutions can go about becoming reflective. 
Developing a reflective approach among students is also largely determined by their having a predisposition towards reflectivity in their attitudes towards learning and relearning. This study suggests that teachers need training that helps them develop sensitivity to their ways of looking at and talking about teaching and developing a positive attitude towards questioning their teaching from themselves and others. We need to create climates in which both the tutor and the student teachers are open to frank critiques of each other's views and personal beliefs. Doing so, would make explicit to the teachers the power of their own and others' thinking and the value of the same in improving their practice.

Finally, despite the CPs' response on their preferred strategies for reflection, a range of reflective strategies are useful for initiating and sustaining reflection. Even though journal writing can be an important way for CPs to record their thoughts and revise formerly held beliefs, socially constructed reflections (those built through interacting with others) can also lead teachers to more in-depth considerations and penetrating ideas (Friere \& Macedo, 1996). Perhaps, we should ensure the provision of numerous opportunities where participants discuss reflections including those from their journal entries.

\section{Conclusion}

From the foregoing, it can be seen that developing reflective practices among students is a complex process in Pakistan and is impacted by such factors such as individual language skills, predispositions of the individual teacher as well as the practices of the teacher education programme. Thus, when we, at teacher education institutions, ask our students to reflect on what they are learning, we need to define this process in relation to the functions and reasons for reflection, what the process will require of them. We also need to consider the structures that need to be put in place to assist the practice of reflection. We must also step back and carefully analyse the social contexts in our classes in which reflection is taking place.

\section{Notes on contributor}

Jane Frances Akinyi Rarieya is Senior Instructor and Coordinator of Certificate Programmes at the Aga Khan University, Institute for Educational Development. She was a high school teacher for several years before she became a teacher educator and worked with teachers in the East African Region (Kenya, Uganda and Tanzania, including Zanzibar) and Pakistan. She has also worked with teachers from Bangladesh and Syria and been involved in school improvement projects in Tanzania and Kenya. Her research activities have been in her areas of interest, which include reflective practice, gender and educational leadership and management. The findings of these studies have been presented at various conferences as well as accepted for publication in several journals. Jane is currently undertaking a doctorate degree in Gender and Educational Management at the University of Keele. 


\section{References}

Bax, S. \& Cullen, R. (2003) Generating and evaluating reflection through teaching practice, TD SIG, 1, 13-20.

Friere, P. \& Macedo, D. (1996) A dialogue: culture, language, and race, in: R. Clift, W. R. Houston \& M. C. Pugach (Eds) Encouraging reflective practice in education: an analysis of issues and programs (New York, Teachers College Press).

Gore, J. M. \& Zeichner, K. (1991) Action research and reflective teaching in pre-service teacher education, Teaching and Teacher Education, 7, 119-136.

Scrivener, J. (1994) Learning teaching (Oxford, Heinemann).

Serafini, F. (2002) Reflective practice and learning, Primary Voices K-6, 10(4), 2-7.

Zeichner, K. (1994) Personal renewal and social reconstruction through teacher research, in: S. Hollingsworth \& H. Sockett (Eds) Teacher research and education reform: ninety-third yearbook of the National Society for the Study of Education (Chicago, University of Chicago Press).

Zeichner, K. M. \& Liston, D. P. (1996) Reflective teaching (Mahwah, NJ, Lawrence Erlbaum). 